American Journal of Applied Sciences 6 (10): 1838-1844, 2009

ISSN 1546-9239

(C) 2009 Science Publications

\title{
Prediction of End-of-Life Strategies for Household Equipments Using Artificial Intelligent
}

\author{
${ }^{1}$ M.M. Noor, ${ }^{1}$ K. Kadirgama, ${ }^{2}$ Aidy Ali, ${ }^{3}$ M.M. Rahman and ${ }^{3}$ Z. Ghazalli \\ ${ }^{1}$ Faculty of Mechanical Engineering, University Malaysia Pahang, Tun Razak Highway, \\ 26300 UMP, Kuantan, Pahang, Malaysia \\ ${ }^{2}$ Department of Mechanical and Manufacturing Engineering, Faculty of Engineering, \\ University Putra Malaysia, UPM, 43400 Serdang, Selangor, Malaysia \\ ${ }^{3}$ Automotive Excellent Center, University Malaysia Pahang, Malaysia
}

\begin{abstract}
Problem statement: Environment issue on the dumping of used household product is a big challenge nowadays. Towards green design, life cycle of a product is very crucial. This study discussed on recycling strategies which include reuse, service, remanufacture and recycle with or without disassembly by using Support Vector Machine Method (SVM). Approach: In early stage of prediction, the input parameters of wear-out life; technology cycle, level of integration, number of parts, reason for redesign and design cycle were incorporated. Six household equipments were studied includes vacuum cleaner, washing machine, television, portable radio and hand held vacuum. Results: The end life predicted results were compared with the previous literature study. Conclusion: The developed End Of Life (EOL) strategies model is good in agreement with existing industry practice.
\end{abstract}

Key words: Environment issue, life cycle engineering, support vector machine, recycling strategy, household equipments

\section{INTRODUCTION}

Green issues and environmental impact due to human activities are always in the priority of all government worldwide. Recycle and reusable is part of the effort. At present, in End-Of-Life (EOL) vehicles, approximately $75-80 \%$ of ferrous and non-ferrous is being recycled. The remaining $20-25 \%$ that contain the mixed of materials such as resin, rubber, glass etc is still disposed ${ }^{[1]}$. According to EU Directive, by 2015, vehicles may be put on the market only if they are reusable and/or recoverable to a minimum of $95 \%$ of total weight $^{[2]}$.

Future generation's survivals of the environmental and non-renewable resource consumption provide the impetus for research on sustainability and improving our natural environment. Countries and companies are establishing goals for achieving sustainable development and reducing resource consumption in hopes of preserving the natural environment for future generations. The first stage in the life cycle of any process is the extraction of resources from their natural reservoirs ${ }^{[3]}$. The extractive activities considered are those used to produce the consumable resources used throughout the life. Material extraction is the process of retrieving valuable materials from layers of the earth's crust. Examples of materials with 21 high extraction costs (environmentally and monetarily) are gold, aluminum and uranium. Recycled materials are nearly always preferable to virgin materials because the:

- Avoid the environmental disruption that virgin material extraction involves

- Generally require less energy in recycling than would be required for virgin material extraction

- Avoid land filling or disposal of the material being recycled $^{[1]}$

Due to parts addling requirements, many product designs could not avoid from manual assembly. On the other hand, many works focusing on recycling cost estimation. The bottom-up type of approach was preferred to where the estimation is conducted based on operation breakdown and summation of detail cost items. Systematically investigated the disassembly sequence and related operations so that disassembly cost can be accurately estimated ${ }^{[4-8]}$. Life Cycle Assessment (LCA), a validation technique, is a broad methodology for identifying environmental burdens that arise from products through the material suppliers, through manufacture, use and disposal ${ }^{[9,10]}$.

Corresponding Author: Aidy Ali, Department of Mechanical and Manufacturing Engineering, Faculty of Engineering, University Putra Malaysia, UPM, 43400 Serdang, Selangor, Malaysia Tel: +603-89466437 
Support Vector Machine (SVM) is a set of related supervised learning methods that used for classification and regression. In viewing an input data as two sets of vectors in n-dimensional space, the SVM will construct a separating hyperplane within the space, which maximizes the margin between the two data sets ${ }^{[13]}$. To calculate the margin, two parallel hyperplanes are constructed, one on each side of the separating hyperplane, which are "pushed up against" the two data sets. Intuitively, a good separation is achieved by the hyperplane that has the largest distance to the neighboring data points of both classes, hence in general the larger the margin the lower the generalization error of the classifier. The category of support vector machines which learns statistically through a kernel function provides a different approach to establish the corresponding decision function ${ }^{[13]}$.

The statistical approaches with the so-called Structure Risk Minimization (SRM) criterion are advantageous in assessing generalization ability and are often employed to avoid an over fitting ${ }^{[14,15]}$. Unlike the parameter settings of the neural networks and fuzzy-net systems, which tie the goal to reduce the errors between actual and predicted responses in the training procedure, the parameters in the SVM are used to maximize the "margin" for a credible separation of the data points. The margin is defined as a street around the separating hyperplane. The wider the margin, the more credible classifier will be. The goal of employing SVM is to create robust predictions rather than the methods described earlier.

The SVM is relatively insensitive to the number of training patterns and the computation complexity, does not depend on the dimensionality of the input space, therefore it can be applied in a large-scale learning system and able to scale better than neural networks or fuzzy-net systems ${ }^{[16]}$. The SVM has demonstrated many potential applications in intelligent manufacturing systems ${ }^{[17]}$. The formulation of SVM embodies the SRM principle, which has been shown to be superior ${ }^{[18]}$ to traditional Empirical Risk Minimization (ERM) principle, employed by conventional neural networks. This study is concentrated on the development of SVM model to predict EOL strategies for household product according to well published literature.

\section{MATERIALS AND METHODS}

End-of-life strategies: EOL strategies describe the approach or method dealing with the product at the endof-life. EOL treatment includes the activities associated with 33 recovering value from the product, through manual labor and/or machinery. The EOL system includes the activities associated with strategic planning and implementation ranging from the collection of products, treatment of those products and the associated impacts to society and environment. Based on work in $^{[19-23]}$, EOL strategies were well defined. The products studied in this work are mostly electronic products, whose functions include heating, cooling, lighting, generation of electricity, transmission of electricity, storage and treatment of information, transportation, motion, communication and ignition of flammable substances ${ }^{[24]}$.

Support vector machine: Support vector machines represent an extension to nonlinear models of the generalized portrait algorithm developed by Vapnik and Lerner ${ }^{[25]}$. The SVM algorithm is based on the statistical learning theory and the Vapnik-Chervonenkis (VC) dimension ${ }^{[26]}$. The statistical learning theory, which describes the properties of learning machines that allow them to give reliable predictions, was reviewed by Vapnik in three books: Estimation of Dependencies Based on Empirical Data, The Nature of Statistical Learning Theory ${ }^{[27]}$ and Statistical Learning Theory ${ }^{[28]}$. In the current formulation, the SVM algorithm was developed at AT and T Bell Laboratories by ${ }^{[29-35]}$. As presented in Fig. 1 and 2, the nonlinear feature function $\varphi$ combines the input space (the original coordinates of the objects) into the feature space, which can even have an infinite dimension.

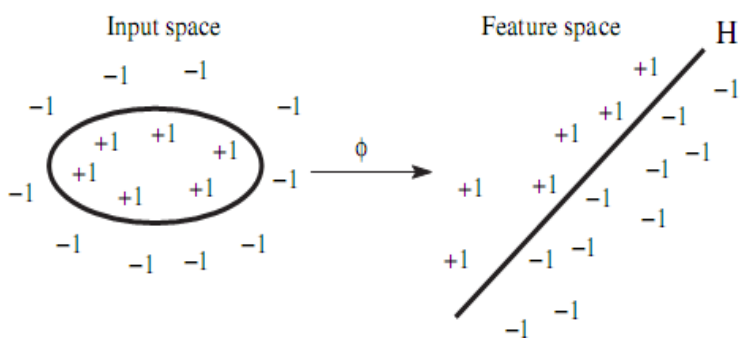

Fig. 1: Nonlinear feature function combines the input space into the feature space ${ }^{[36]}$

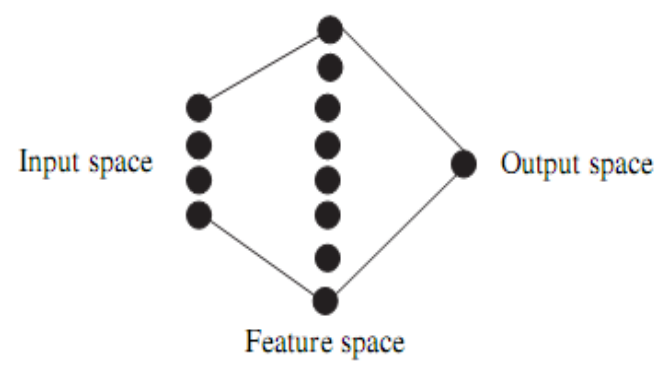

Fig. 2: Support vector machines map the input space into a high-dimensional feature space ${ }^{[36]}$ 
Because the feature space is high dimensional, it is not practical to use directly feature functions $\varphi$ in computing the classification hyperplane ${ }^{[36]}$. Instead, the nonlinear mapping induced by the feature functions is computed with special nonlinear functions called kernels. Kernels have the advantage of operating in the input space, where the solution of the classification problem is a weighted sum of kernel functions evaluated at the support vectors.

Note that in pattern recognition, descriptors are usually called "features", but in SVM, "features" have another meaning, so one must make a clear distinction between "descriptors" and "features" ${ }^{\text {"[36] }}$. A descriptor can be any experimentally measured or theoretically computed quantities that describes the structure of a pattern, including, for example, spectra and composition for chemicals, agricultural products, materials, biological samples; graph descriptors and topological indices; indices derived from the molecular geometry and quantum calculations; industrial process parameters; chemical reaction variables; microarray gene expression data; and mass spectrometry data for proteomics ${ }^{[36]}$.

An $n$-dimensional pattern (object) $x$ has $n$ coordinates, $\mathrm{x}=\left(\mathrm{x}_{1}, \mathrm{x}_{2}, . ., \mathrm{x}_{\mathrm{n}}\right)$, where each $\mathrm{x}_{\mathrm{i}}$ is a real number, $x_{i} \in R$ for $i=1,2, \ldots, n$. Each pattern $x_{j}$ belongs to a class $y_{j} \in\{-1,+1\}$. Consider a training set $T$ of $m$ patterns together with their classes, $T=\left\{\left(\mathrm{x}_{1}, \mathrm{y}_{1}\right)\right.$, $\left.\left(\mathrm{x}_{2}, \mathrm{y}_{2}\right), \ldots,\left(\mathrm{x}_{\mathrm{m}}, \mathrm{y}_{\mathrm{m}}\right)\right\}$ Consider a dot product space $\mathrm{S}$, in which the patterns $\mathrm{x}$ are embedded, $\mathrm{x}_{1}, \mathrm{x}_{2}, \ldots, \mathrm{x}_{\mathrm{m}} \in \mathrm{S}$. Any hyperplane in the space $S$ can be written as ${ }^{[36]}$ :

$$
\{\{\mathrm{x} \in \mathrm{S} \mid \mathrm{w} \cdot \mathrm{x}+\mathrm{b}=0\}\}, \mathrm{w} \in \mathrm{S}, \mathrm{b} \in \mathrm{R}
$$

The dot product $\mathrm{w} . \mathrm{x}$ is defined by:

$$
\mathrm{w} \cdot \mathrm{x}=\sum_{\mathrm{i}=1}^{\mathrm{n}} \mathrm{w}_{\mathrm{i}} \mathrm{x}_{\mathrm{i}}
$$

A hyperplane w. $\mathrm{x}+\mathrm{b}=0$ can be denoted as a pair $(w, b)$. A training set of patterns is linearly separable if at least one linear classifier exists defined by the pair $(w, b)$, which correctly classifies all training patterns. All patterns from class +1 are located in the space region defined by $w \cdot x+b>0$ and all patterns from class -1 are located in the space region defined by $w \cdot x+b<0$. Using the linear classifier defined by the pair $(w, b)$, the class of a pattern $x_{k}$ is determined with ${ }^{[36]}$.

$$
\operatorname{class}\left(\mathrm{x}_{\mathrm{k}}\right)= \begin{cases}+1, & \mathrm{w} \cdot \mathrm{x}_{\mathrm{k}}+\mathrm{b}>0 \\ -1, & \mathrm{w} \cdot \mathrm{x}_{\mathrm{k}}+\mathrm{b}<0\end{cases}
$$

The distance from a point $\mathrm{x}$ to the hyperplane defined by $(w, b)$ is ${ }^{[36]}$ :

$$
\mathrm{d}(\mathrm{x} ; \mathrm{w}, \mathrm{b})=\frac{|\mathrm{w} \cdot \mathrm{x}+\mathrm{b}|}{\|\mathrm{w}\|}
$$

\section{RESULTS}

The products' classified EOL strategy and industry practice are compared and analyzed. Strong agreement between SVM prediction and industry practice were validates the method. It shows that SVM succeeds in classification of product EOL strategies in agreement with current industry practices. The mismatch between SVM and current best practice identifies areas for improvement in design and business practices. The first phase starts with gathering the information of the parts and components and classification of the automobiles. Then, the next step is to identify the characteristics of the parts and components. The characteristics are based on the ELDA developed by Rose. These components are as follows Rose ${ }^{[37]}$ :

- Wear out life-the length of time from product purchase until the product no longer meets original functions. For instance, a computer has a wear-out life of approximately 7-10 years

- Technology cycle-the length of time that the product will be on the leading edge of technology before new technology makes the original product obsolete. For example, the technology cycle of computers is about 6 months, 1 year

- Level of integration-the interrelation between modules and functions. For example, if there are many unique functions for each module, the level of integration is high

- Number of parts-the number of assemblies in the product that is relevant to EOL treatment

- Reason for redesign-any original design, evolutionary design, functional improvement, aesthetic change, feature change which depend on customer demand, competitor behavior and scientific progress

- Design cycle-the frequency that a design team redesigns the product. For example, an automobile has the design cycle of 2-4 years

The classification uses the ratio between product wear-out and technology cycles. In Rose et al. ${ }^{[38]}$, the mapping of wear-out life to technology cycle is used to make recommendations for end-of-life treatment. 
Am. J. Applied Sci., 6 (10): 1838-1844, 2009

Table 1: Product characteristics according to Rose $\mathrm{e}^{[25]}$

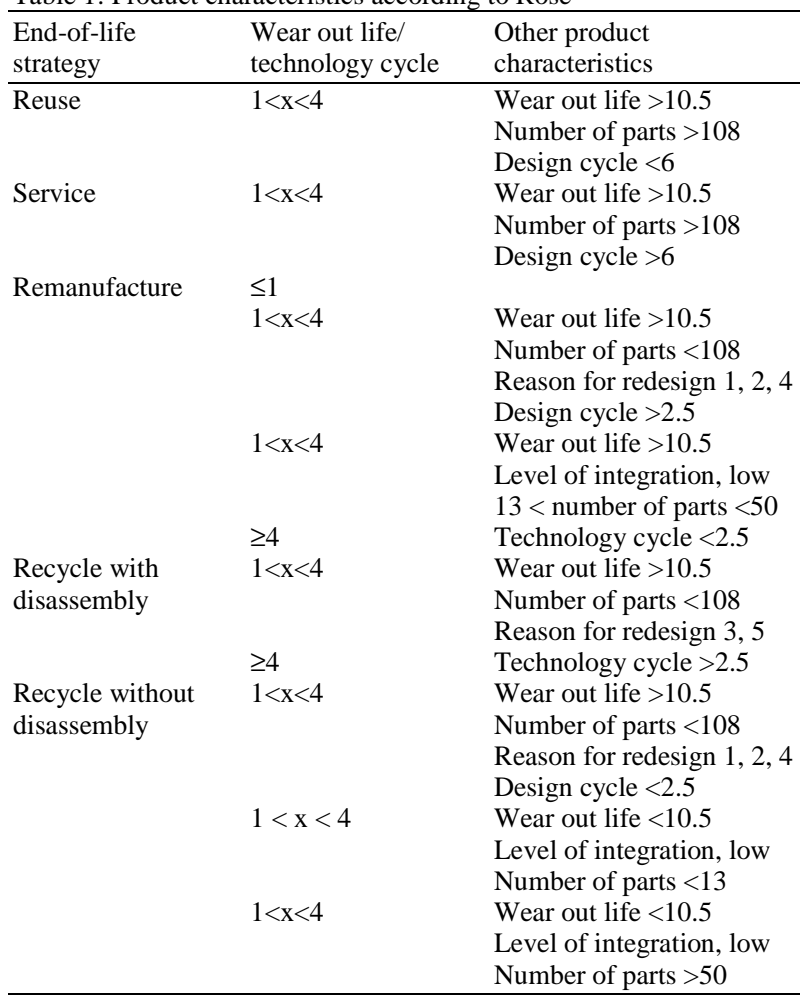

EOL strategies and critical product characteristics are following with information ${ }^{[37]}$. According to Rose ${ }^{[37]}$ the characteristics that are important for the reuse of a product are long wear-out life, high number of parts and design cycle less than six years. The product characteristics that affect servicing of a product are long wear-out life, high number of parts and long design cycle. Products that should be remanufactured range the divisions set by the ratio of wear-out life to technology cycle. Remanufactured products can have long wearout life, moderate number of parts, various reasons for redesign and design cycle greater than 2.5 years $^{[37]}$. All the characteristics are shown in Table 1 . The definitions are shown in Table 2.

The ability to classify strategies enables companies to design future products that attain higher level on the end-of-life hierarchy. Once again, the definitions of end-of-life strategies are given to guide the following discussion about the validation method ${ }^{[37]}$.

The procedure for collecting the current end-of-life strategies practiced in industry included observing and questioning recycling organizations, producers and consumers. As well, the legislation requiring a particular end-of-life treatment and internet sales were monitored to have a better view of the end-of-life treatment situation ${ }^{[37]}$. With the responses, if the answers were consistently the same (for example, reuse) and then the product end-of-life strategy was reuse.
Table 2: Definitions of end-of-life strategies

\begin{tabular}{|c|c|}
\hline Name & Definition \\
\hline Reuse & $\begin{array}{l}\text { Reuse is the second hand trading of product for use } \\
\text { as originally designed }\end{array}$ \\
\hline Service & $\begin{array}{l}\text { Servicing the product is another way of extending } \\
\text { the life of a durable product or component parts by } \\
\text { repairing or rebuilding the product using service } \\
\text { parts at the location where the product is being used }\end{array}$ \\
\hline Remanufacture & $\begin{array}{l}\text { Remanufacturing is a process in which reasonably } \\
\text { large quantities of similar products are brought into } \\
\text { a central facility and disassembled. Parts from a } \\
\text { specific product are not kept with the product but } \\
\text { instead they are collected by part type, cleaned, } \\
\text { inspected for possible repair and reuse. } \\
\text { Remanufactured products are then reassembled on } \\
\text { an assembly line using those recovered parts and } \\
\text { new parts where necessary }\end{array}$ \\
\hline $\begin{array}{l}\text { Recyc } \\
\text { disass }\end{array}$ & $\begin{array}{l}\text { Recycling reclaims material streams useful for } \\
\text { application in products. Separation into material } \\
\text { fractions increases the value of the materials } \\
\text { recycled by removing material contaminants, } \\
\text { hazardous materials, or high value components. The } \\
\text { components are separated mostly by manual } \\
\text { disassembly methods. }\end{array}$ \\
\hline $\begin{array}{l}\text { Recycle without } \\
\text { disassembly }\end{array}$ & $\begin{array}{l}\text { The purpose of shredding is to reduce material size } \\
\text { to facilitate sorting. The shredded material is } \\
\text { separated using methods based on magnetic, density } \\
\text { or other properties of the materials. }\end{array}$ \\
\hline Disposal & $\begin{array}{l}\text { This end-of-life strategy is to landfill or incinerate } \\
\text { the product with or without energy recovery }\end{array}$ \\
\hline
\end{tabular}

If there are conflicting answers, the one higher on the hierarchy is labeled best and the one lower labeled average. If multiple answers were given, then the observation most frequently cited is used as the average ${ }^{[37]}$. The following present the observations of industry practice and the classification by SVM and Rose $^{[37]}$ are shown in Table 3.

\section{DISCUSSION}

The examination and analysis of Table 3 shows the differences between the EOL strategies recommended by SVM, current best practice by industry and average practice by industry. Average industry practices end of life strategies for vacuum cleaner is disposal, meanwhile SVM predict it as recycle without disassembly. Same goes to portable radio where SVM predict the recycle strategies is recycle with disassembly, meanwhile average industry practice disposal. According to $\operatorname{Rose}^{[37]}$ this is due to many household and electronic products in the United States the current average EOL strategy is recycle, with or without some disassembly and disposal. SVM predict 2 product EOL strategies with recycle without disassembly, 3 products with recycle with disassembly and 1 remanufacture. Figure 3 shows the difference of end of life strategies predict by SVM with real practice of industry. 
Am. J. Applied Sci., 6 (10): 1838-1844, 2009

Table 3: Strategy classified by SVM and the observed industry practice

\begin{tabular}{llll}
\hline Products & Sector vector machine & Best industry & Average industry \\
\hline Washing machine & Recycle without disassembly & Recycle without disassembly & Recycle without disassembly \\
Vacuum cleaner & Recycle without disassembly & Recycle without disassembly & Disposal \\
Television & Recycle with disassembly & Recycle with disassembly & Recycle with disassembly \\
Washing machine & Recycle with & Recycle with & Recycle with \\
Electric motor & disassembly & disassembly & disassembly \\
Hand held vacuum & Remanufacture & Remanufacture & Recycle without disassembly \\
Portable radio & Recycle with disassembly & Recycle with disassembly & Disposal \\
\hline
\end{tabular}

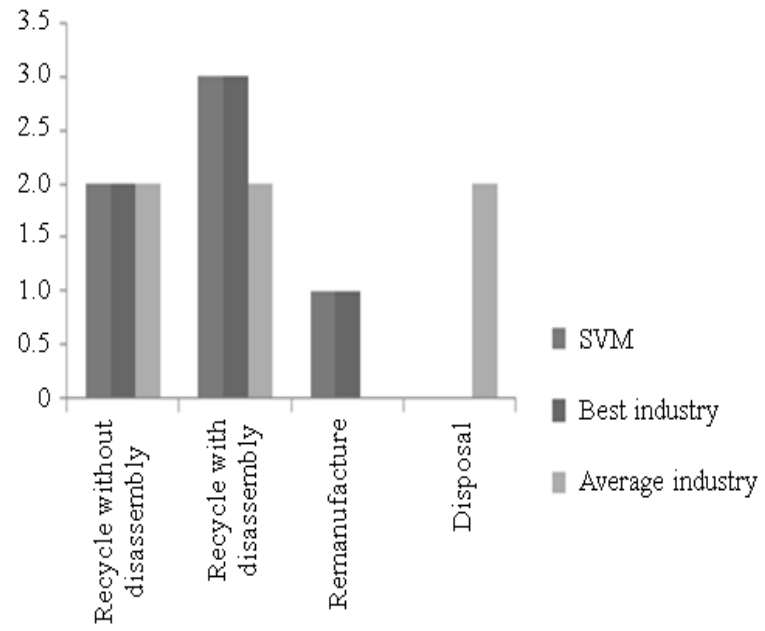

Fig. 3: Difference of end of life strategies predict by SVM with real practice of industry

\section{CONCLUSION}

Household equipments were analyzed and the artificial intelligent method was employed to predict the EOL strategies. The propose technique aim at integrating the design for remanufacturing techniques with the application of SVM helps designer make decision by identifying the suitable EOL path of the household product. Six characteristics were used to determine the core criteria in the first phase. Through SVM model, the cores are expected able to be divided into remanufacture, service, recycle with disassembly and recycle without disassembly and disposal. The prediction of the three household products shows that SVM models can be used to predict end of life strategies all household products.

\section{ACKNOWLEDGEMENT}

The financial support by Malaysian Government through MOSTI (03-01-16-SF0013) and University Malaysia Pahang is grateful acknowledged.

\section{REFERENCES}

1. Shallari, K.N. and J.L. Pineau, 2003. End-of-Life vehicle recycling in the European Union. J. Minerals Metals Mater., 55: 345-351. http://www.tms.org/pubs/journals/JOM/jombymont h.asp? year $=2003$

2. 2005/64/EC. The reusing, recycling and recovering of motor vehicles. August 8, 2006. http://europa.eu/scadplus/leg/en/lvb/n26102.htm

3. Graedel, T.E., 1995. Allenby, Brad, Industrial Ecology. 2nd Edn.. Prentice Hall, New Jersey, USA., pp: 35-56.

4. Boothroyd, G. and L. Atling, 1992. Design for assembly and disassembly. CIRP Ann., 41: 625-636. http://cat.inist.fr/?aModele $=$ afficheN\&cpsidt $=4463$ 733

5. Gungor, A. and S.M. Gupta, 1997. An evaluation methodology for disassembly process. Comput. Ind. Eng., 33: 329-332. DOI: 10.1016/S03608352(97)00104-6

6. Zhang, H.C. and T.C. Kuo, 1997. A graph-based disassembly sequence planning for EOL product recycling. Proceeding of the 21st IEEE/CPMT International Symposium on Electronics Manufacturing Technology, Oct. 13-15, IEEE Xplore Press, Austin, TX., USA., pp: 140-151. DOI: 10.1109/IEMT.1997.626890

7. Feldmann, K., S. Trautner, H. Lohrmann and K. Melzer, 2001. Computer-based product structure analysis for technical goods regarding optimal end-of-life strategies. J. Eng. Manufact., 215: 684-93. http://cat.inist.fr/?aModele $=$ afficheN\&cpsidt $=1000$ 369

8. Ichikawa, Y., 2001. Practice and Case Study of DFE. Ohmsha Publishing Co., Tokyo.

9. SETAC., 1991. A Technical Framework for LifeCycle Assessments. Society of Environmental Toxicology and Chemistry, Washington, DC.

10. EPA., 1993. Life-Cycle Assessment: Inventory Guidelines and Principles. Environmental Protection Agency-Office of Research and Development, Washington DC., US. 
11. Brezet, H., A. Stevels and J. Rombouts, 1999. LCA for EcoDesign: The Dutch experience. Proceeding of the 1st International Symposium on Environmentally Conscious Design and Inverse Manufacturing, (ECDIM'99), IEEE Computer Society, New Jersey, USA., pp: 36-40.

12. Stevels, A.L.N., 2000. Integration of Ecodesign into Business. In: Mechanical Life Cycle Handbook: Good Environmental Design and Manufacturing, Hundal, M.S. (Ed.). Marcel Dekker, New York, pp: 200.

13. Cristianini, N. and J. Shawe-Taylor, 2000. Support Vector Machines and other kernel-based learning methods, Cambridge University Press, Cambridge, ISBN: 0521780195, pp: 189.

14. Vapnik, V.N., 1995. The Nature of Statistical Learning Theory. Springer-Verlag, New York.

15. Vapnik, V.N., 1998. Statistical Learning Theory. 1st Edn., John Wiley and Sons, New York, ISBN: 10: 0387945598, pp: 188.

16. Joachims, T., 1998. Making Large-Scale Support Vector Machine Learning Practical. In: Advances in Kernel Methods: Support Vector Machines, Scholkopf, B., C. Burges and A. Smola (Eds.). MIT Press, Cambridge, MA., ISBN: 10: 0262194163 , pp: 386.

17. Cho, S., S. Asfour, A. Onar and N. Kaundinya, 2005. Tool breakage detection using support vector machine learning in a milling process. Int. J. Mach. Tool. Manuf., 45: 241-249. DOI: 10.1016/j.ijmachtools.2004.08.016

18. Gunn, S.R., M. Brown and K.M. Bossly, 1997. Network performance assessment for neuro-fuzzy data modeling. Intel. Data Anal., 1208: 313-323. DOI: $10.1007 / \mathrm{BFb} 0052824$

19. Overby, C., 1979. Product design for recyclability and life extension. Proceedings of the ASEE Annual Conference.

20. Ishii, K., C.F. Eubanks and P. Di Marco, 1994. Design for product retirement and material lifecycle. Mater. Des., 15: 225-233. http://mml.stanford.edu/publications/1994/1994.M DJ.Ishii.pdf

21. Luttrop, C., 1997. Based on prepared disassembly and sorting. Machine Design, Swedish Design for Disassembly: Environmentally Adapted Product Development Royal Institute of Technology (KTH).

22. Mackenzie, D., 1997. Green Design: Design for Environment. Laurence King, UK., ISBN: 10: 1856690962, pp: 176.
23. Nilsson, J., 1998. The Recycling Aspect in Product Development-Framework for a Systematic Approach. Science and Technology, Linkoping, Linkoping University.

24. Hedemalm, P., P. Carlsson and V. Palm, 1995. Waste from Electrical and Electronic Products-A Survey of the contents of materials and hazardous substances in electric and electronic products. Copenhagen, Nordic Council of Ministers.

25. Vapnik, V. and A. Lerner, 1963. Pattern recognition using generalized portrait method. Automat. Remote Control, 24: 774-780. http://www.kernelmachines.org/publications/VapLer63

26. Vapnik, V. and A. Chervonenkis, 1974. Theory of Pattern Recognition. Nauka, Moscow, Russia.

27. Vapnik, V., 1995. The Nature of Statistical Learning Theory. Springer, New York.

28. Vapnik, V., 1998. Statistical Learning Theory. Wiley-Interscience, New York.

29. Cortes, C. and V. Vapnik, 1995. Support-vector networks. Mach. Learn., 20: 273-297.

30. B. Scholkopf, K.K. Sung, C.J.C. Burges, F. Girosi, P. Niyogi, T. Poggio and V. Vapnik, 1997. Comparing support vector machines with Gaussian kernels to radial basis function classifiers. IEEE Trans. Sign. Process., 45: 2758-2765. http://cat.inist.fr/?aModele $=$ afficheN\&cpsidt $=2074$ 600

31. Chapelle, O., P. Haffner and V.N. Vapnik, 1999. Support vector machines for histogram-based image classification. IEEE Trans. Neural Network, 10:

1055-1064. http://www.ncbi.nlm.nih.gov/pubmed/18252608

32. Drucker, H., D.H. Wu and V.N. Vapnik, 1999. Support vector machines for spam categorization. IEEE Trans. Neural Network, 10: 1048-1054. http://www.ncbi.nlm.nih.gov/pubmed/18252607

33. Vapnik, V.N., 1999. An overview of statistical learning theory. IEEE Trans. Neural Network, 10: 988-999. DOI: 10.1109/72.788640

34. Vapnik, V. and O. Chapelle, 2000. Bounds on error expectation for support vector machines. Neural Comput., $\quad$ 12: 2013-2036. http://portal.acm.org/citation.cfm?id=1246401

35. Guyon, J. Weston, S. Barnhill and V. Vapnik, 2002. Gene selection for cancer Classification using support vector machines. Mach. Learn., 46: 389-422. DOI: 10.1023/A:1012487302797 
36. Ovidiu Ivanciuc, 2007. Applications of support vector machines in chemistry. Rev. Comput. Chem., 23: 291-400. http://www.ivanciuc.org/Files/Reprint/Ivanciuc_S VM_CCR_2007_23_291.pdf

37. Rose, C.M., 2000. Design for environment: A method for formulating product end-of-life strategies. Ph.D. Dissertation, Department of Mechanical Engineering, Stanford University, Anm Abror, Michigan: Bell and Howell Information and Learning Company.
38. Rose, C.M. and K. Ishii, 1999. Product end-of-life strategy categorization design tool. J. Elect. Manufact., 9: 41-51. 